\title{
Letters
}

\section{Three quarters of delegates drove to conference on impact of environment on health}

EDITOR-A conference was organised recently in Northern and Yorkshire region to promote joint working between health and local authorities on environmental issues. As the delegates would include potential leaders of any resulting initiatives we were interested to see how they travelled to the conference. Travel information was sent out before the event, and the venue was chosen for its accessibility: it was on a bus route and a short walk from the railway station.

A question on the conference evaluation form asked about the method of transport used, including whether cars carried passengers, the fuel used, and engine size. We also asked the name of the delegate's employer, the delegate's job title, and whether he or she belonged to an environmental pressure group (not defined).

Most of the delegates to the conference, which was on the impact of the environment on health, travelled by car, even though the venue could be reached easily by public transport. Altogether 165 people attended, of whom $109(66 \%)$ returned the evaluation form. Three quarters (83) came by car, more than half travelling alone. Twenty used the train, five cycled, and one came by bus. Most worked in health care (48 were employed by district health authorities, trusts, the NHS Executive, or the Department of Health), while 39 were from local authorities. Twenty five were members of an environmental pressure group.

Seniority increased the likelihood that travel would be by car $\left(\chi^{2}\right.$ test for trend $\mathrm{P}<0.0001)$, but no relation was found between increasing seniority and car engine size. Delegates named 14 groups as environmental pressure groups to which they belonged (table), but none mentioned their employing organisation. All of the cyclists listed at least one membership, and, overall, members of any environmental group were more likely to travel by public transport $\left(\chi^{2}\right.$ $=21.56, \mathrm{P}<0.0001, \mathrm{df}=1$ ).

Public sector workers seem to be supporting the dominance of the car culture; perhaps their employers should be asking how other forms of transport can be promoted. Many people drove cars leased to them through their work, and such schemes usually offer few incentives to choose a small engine size or a vehicle that is economical on fuel. A minimum annual mileage may also encourage greater use of vehicles; providing parking
Organisations named as environmental pressure groups of which delegates at conference were members

\begin{tabular}{lc} 
Organisation & $\begin{array}{c}\text { No of } \\
\text { members }\end{array}$ \\
\hline Friends of the Earth & 6 \\
\hline Sustrans* & 5 \\
\hline Greenpeace & 4 \\
\hline Royal Society for the Protection of Birds & 3 \\
\hline Cyclists Touring Club & 3 \\
\hline National Trust & 2 \\
\hline Chartered Institute of Environmental Health & 2 \\
\hline Green Party & 1 \\
\hline Medact & 1 \\
\hline WWF† & 1 \\
\hline Faculty of Public Health Medicine & 1 \\
\hline United Nations Environment and Development UK & 1 \\
\hline Public Health Alliance & 1 \\
\hline Food Poverty Network & 1 \\
\hline Total No of memberships (25 people) & 32 \\
\hline
\end{tabular}

*Charity promoting cycle paths.

†Formerly World Wildlife Fund.

spaces at places of work can add to traffic volume and pollution in towns and cities.

Our experience suggests that if health and local authorities are to lead the way to a healthier nation then transport policies for their own staff may be a good place to start.

Barbara Hanratty Senior registrar in public health medicine

Will Patterson Consultant in public health medicine North Yorkshire Health Authority, York YO1 1PE

\section{Audit of child protection procedures in an A\&E department}

\section{Notes of all previous attendances in} Sheffield can be checked

EDIToR-Sidebotham and Pearce's audit of child protection procedures in an accident and emergency department should raise general awareness that children in any such departments need special consideration. ${ }^{1}$ It should also raise specific awareness that non-accidental injury often presents to accident and emergency departments.

It is interesting that the nurses seem to have been given the job of scoring the risk factors for abuse in this study and that the doctors were given the job of auditing nurse practice. All accident and emergency staff should be informed and aware of the possibility of non-accidental injury, although the checking system would be carried out more efficiently if it was the responsibility of one clearly identified individual, in this case the initial assessment nurse. ${ }^{2}$

The accident and emergency department at Sheffield Children's Hospital has a system of amalgamating a child's notes so that every previous attendance to the department can be checked at each new attendance. In accident and emergency one does not have the benefit that general practitioners have of having known the child and family over a period. Every clue to the child's health and lifestyle is needed to put the current attendance in context.

There has long been an alerting system not only for children officially on the child protection register but also for families who have caused concern to other health professionals such as paediatricians, health visitors, and general practitioners. Family problems such as alcoholism and substance abuse have an impact on children and their care. With the modern practice of working with parents and registering as few children as possible for as short a time as possible, there are many children and families who need

\section{Advice to authors}

We receive more letters than we can publish:we can currently accept only about one third. We prefer short letters that relate to articles published within the past four weeks. We also publish some "out of the blue"letters, which usually relate to matters of public policy.

When deciding which letters to publish we favour originality, assertions supported by data or by citation, and a clear prose style. Letters should have fewer than 400 words (please give a word count) and no more than five references (including one to the BMJ article to which they relate);references should be in the Vancouver style. We welcome pictures.

Letters, whether typed or sent by email, should give each author's current appointment and full address. Letters sent by email should give a telephone and fax number when possible. We encourage you to declare any conflict of interest. Please send a stamped addressed envelope if you would like to know whether your letter has been accepted or rejected.

We may post some letters submitted to us on the world wide web before we decide on publication in the paper version. We will assume that correspondents consent to this unless they specifically say no.

Letters will be edited and may be shortened. 
extra assessment, care, and support when children are not officially registered.

I believe that there are even broader and more subtle considerations when trying to define a child at risk. The paediatric influence in accident and emergency departments would be best served by increasing the number of accident and emergency consultants with a special interest in paediatrics or at least by having a paediatrician linked closely to each department.

P O Brennan Consultant in paediatric accident and emergency

Accident and Emergency Department, Children's Hospital, Sheffield S10 2TH

1 Sidebotham PD, Pearce AV. Audit of child protection procedures in accident and emergency department to identify children at risk of abuse. BMJ 1997;315:855-7. (4 October)

\section{General practitioners need training in child protection}

EdIToR-We support Sidebotham and Pearce when they recommend improvements in child protection procedures in accident and emergency departments by means of clear protocols, regular staff training, and increased levels of communication. ${ }^{1}$ Though appreciable numbers of children attend accident and emergency departments, general practitioners are now the first point of contact for most child health problems. They are therefore extremely likely to regularly encounter children who are at risk of abuse. General practitioners could undertake a substantial role in the overall child protection process in view of their increased commitment to health surveillance programmes. Experience to date, however, indicates that they have a relatively peripheral involvement in this area of their work, particularly with respect to attendance at child protection case conferences and participation in training events. ${ }^{2}$

We recognise that child protection issues present general practitioners with specific challenges. Many fear that the unique relationships that they hold with families may be compromised when they invoke child protection procedures, while others express anxiety about the medicolegal consequences of sharing confidential information with social services. ${ }^{3}$ The Department of Health's publication Clarification of Arrangements between the NHS and Other Agencies, while recognising these difficulties, is clear that general practitioners are required to place the safety and welfare of children above all other considerations and to participate fully in child protection procedures. ${ }^{4}$

We undertook five focus group discussions among 38 members of primary healthcare teams in the West Midlands in 1996 to identify themes relevant to child protection issues as they present in a primary care setting. We found that none of the 16 general practitioners who participated had received sufficient training in child protection. All showed impaired awareness of both their own role in the child protection process and local referral procedures. A similar lack of awareness of child protection procedures among general practitioners has been found elsewhere. ${ }^{5}$ Not surprisingly, child protection work was a source of anxiety and uncertainty to them. In addition to practice based multidisciplinary training in child protection, participants requested simple, A4-size flow diagrams that summarised local referral procedures.

Implementation of practice based clinical guidelines that reflect the policies of local area child protection committees would be a step forward. The specific training needs of general practitioners will need to be addressed by area child protection committees and those involved in postgraduate education. However, general practitioners must recognise the unique role they could have in this area and show further commitment to the protection of children from abuse and neglect.

MJ Bannon Consultant paediatrician Child Health Unit, Northwick Park and St Mark's Hospital NHS Trust, Northwick Park Hospital,

Harrow, Middlesex HA1 3U

Y H Carter Professor

Department of General Practice and Primary Care, St Bartholomew's and the Royal London School of Medicine and Dentistry, Queen Mary and Westfield College, London E1 4NS

1 Sidebotham PD, Pearce AV. Audit of child protection procedures in accident and emergency department to identify children at risk of abuse. BMJ 1997;315:855-7. (4 October.) 2 Hallett C, Birchall E. Co-ordination and child protection. London: HMSO, 1992

3 Bannon MJ, Carter YH. Confidentiality issues in child protection and the general practitioner. Practitioner 1991;235. 826-31

4 Department of Health, Child Protection. Clarification of Arrangements between the NHS and Other Agencies. London: HMSO, 1995

5 Hales P. The launch of the child protection audit pack for primary health care teams. In: Proceedings of 3rd conferprimary healh care teans. Hn. Procedings of 3rd conferChild Abuse and Neglect, Edinburgh, 1997.

\section{Checks on children in Southend have to} be via a social worker

EDITOR-Sidebotham and Pearce rightly emphasised the important role of accident and emergency departments in the recognition of non-accidental injury. ${ }^{1}$ The true incidence of non-accidental injury in paediatric attenders at accident and emergency departments is unknown, but few accident and emergency departments will identify more than a small proportion of cases. We should at least be able to offer adequate protection to those already on the child protection register. The authors state that they checked the register but do not make clear how they were able to do this. My department too used to check a child's name and date of birth against the register, initially on a simple rotary file and more recently in a secure file on the hospital computer. Recently, however, the child protection authorities have refused to allow us copies of the register, insisting that any access to it has to be via a duty social worker. This entails telephone calls and lengthy delays and is clearly impossible for all of the 30-40 paediatric attendances each day in my department.

In these days of sophisticated and well secured electronic data it should be possible for all accident and emergency departments to check children rapidly and accurately against the local register. The Department of
Health should seek ways of extending this to national registers to prevent children falling through the net by attending departments in neighbouring districts. If suspicion of nonaccidental injury is limited to those with risk factors or with overtly suspicious injuries we will continue to overlook substantial numbers of abused children.

J E Porter Accident and emergency consultant Southend Hospital, Westcliff on Sea, Essex SS20 0RY

1 Sidebotham PD, Pearce AV. Audit of child protection prochildren at risk of abuse BMJ 1997.315.855-7. (4 October)

\section{Testing of PRODIGY continues}

EDITOR-Walton et al correctly state that "both CAPSULE and PRODIGY [computer support systems for prescribing] represent attempts to bring the benefits of computer support ... into primary care" and highlight the lack of relevant research at the primary level. ${ }^{1}$ Their paper provides evidence that computers influence prescribing in general practice, with the potential economic benefits identified by the Audit Commission. Analysis of the cost effectiveness of prescribing interventions needs, however, to be presented within a wider assessment of overall healthcare costs, and the notions of rational and quality prescribing should be broadly defined.

PRODIGY's clinical recommendations are not restricted to drug prescribing but cover the full range of management issues for over 200 clinical conditions common to general practice. Options presented include referral or investigation, non-drug treatment, and patient information leaflets. Recommendations are produced by a multidisciplinary team after a structured literature search and review of the evidence; they are rigorously validated by a panel drawn from the Royal Pharmaceutical Society, Royal College of General Practitioners, and General Medical Services Committee. The PRODIGY project team, funded by the NHS Executive, is doing pioneering work at the Sowerby Centre towards developing a robust method for integrating evidence into rational, educational, and interventional guidance. Phase two of the trial also included a large amount of patient related data from the electronic medical records to enable the system to present information tailored adequately to the individual.

As Walton et al state, "it is important that the effects of decision support systems for prescribing are carefully evaluated both during their development cycle and in real life." PRODIGY has been available for use in consultations with real patients to over 750 general practitioners nationally, with eight different clinical systems being used. The project has achieved the delivery of prescribing support on current practice computer systems, as requested by the general practitioners interviewed in Walton et al's study, and the experience of users of PRODIGY has contributed to the innovative development process. The rigorous "real 
life" evaluation of PRODIGY represents a clear advance on the testing performed on a laptop computer by 42 local doctors, using simulated cases, as described in the paper.

Laboratory evaluation is an important aspect of the development of health information systems, but such systems should undergo two further types of trial if they are to be fully evaluated before implementation. ${ }^{2}$ PRODIGY has been submitted to type 2 (real life) testing; the COGENT project (information available at http://www.ncl.ac. $\mathrm{uk} /$ ncenthsr/research/cogent/index.html), which uses a common technology and is synergistic with PRODIGY, is a type 3 trial.

Ian Purves Head

Gary Nestor Research manager

Katherine Williams PRODIGY communications coordinator

Sowerby Centre for Health Informatics at Newcastle, University of Newcastle, Primary Care Development Centre, Newcastle General Hospital, Newcastle upon Tyne NE4 6BE

1 Walton RT, Gierl C, Yudkin P, Mistry H, Vessey MP, Fox J. Evaluation of computer support for prescribing (CAP SULE) using simulated cases. BMJ 1997;315:791-5. (27 September.)

2 Donaldson LJ. From black bag to black box: will computers improve the NHS? BMJ 1996;312:1371-2.

\section{Survey of French prison found that injecting drug use and tattooing occurred}

EDITOR-Injecting drug use in prison is common in several northern European countries, ${ }^{1}$ though the proportion of cases of AIDS attributable to injecting drug behaviour is higher in prisons in southeastern France (42\%). ${ }^{2}$ In 1996 about a fifth of the 58000 prisoners in French prisons were injecting drug users. A study in Marseilles prison (2000 prisoners) in 1992 estimated the seroprevalence of HIV to be $7.1 \%$ among male prisoners and $13.1 \%$ among female prisoners and showed it to be higher among people who had been in prison previously. ${ }^{3}$ We investigated risk behaviours among injecting drug users in Marseilles prison.

We invited inmates who had been in Marseilles prison for three months to answer an anonymous self administered questionnaire. Altogether 520 (55\%) of 942 male and $54(77 \%)$ of 70 female inmates responded; 455 inmates (410 male, 45 female) answered the questionnaire about risky behaviours in prison. Among the 120 inmates who had ever injected drugs, 68 had injected during the 12 months before being imprisoned (active injecting drug users). Among the 102 injecting drug users who declared having been tested for HIV and informed us about their HIV status, 31 were infected. Nine of 68 active injecting drug users declared having injected drugs during the first three months of their imprisonment; female inmates injected more commonly than male inmates $(5 / 12(42 \%) v$ $4 / 56 \quad(7 \%), \quad \mathrm{P}=0.006)$. Of these nine injecting drug users, four shared paraphernalia in prison, of whom one was HIV posi- tive. Inactive injecting drug users did not report injecting in prison.

Thirty eight of 427 inmates reported having been tattooed during the first three months of imprisonment; six of these were HIV positive. Tattooing was more common among those who did than those who did not inject drugs $(17 / 118$ (14\%) v 20/307 $(7 \%) \mathrm{P}=0.009)$ and among injecting drug users who injected inside prison than injecting drug users who did not $(4 / 9(44 \%) v$ $7 / 59(12 \%), \mathrm{P}=0.03)$.

This survey shows that injecting drug use was commonly reported by users in a prison in France, with a large excess among women. These results must be confirmed by a larger systematic study, but they support the policy of the French Penitentiary Administration, which has authorised use of bleach in prison since January 1997. This policy should be implemented rapidly and sustained by health education, access to medicated withdrawal, and maintenance treatment for opiate dependence. Because of the high prevalence of HIV infection and hepatitis C among injecting drug users $(91 \%){ }^{4}$ pilot needle exchange programmes should be started, especially among women, and safe equipment for tattooing made available. ${ }^{5}$

We acknowledge the prison staff and inmates who participated in this study, which was supported by grants from the Agence Nationale de Recherche sur le Sida and the European Commission.

M Rotily Director of studies

C Delorme Statistician

Y Obadia Director

Observatoire Régional de la Santé Provence Alpes Côte d'Azur, 13006 Marseilles, France

N Escaffre Psychosociologist

INSERM U 379, Institut Paoli Calmettes, 13009 Marseilles

A Galinier-Pujol Head of medical unit

Centre Pénitentiaire de Marseille, 13009 Marseilles

1 Bird AG, Gore SM, Hutchinson SJ, Lewis SC, Cameron S, Burns S. Harm reduction measures and injecting inside prison versus mandatory drugs testing: results of a cross sectional anonymous questionnaire survey. BMJ 1997 315:21-4. (5 July)

2 Réseau National de Santé Publique. Linfection à VIH en France: tendances actuelles-Iournée mondiale du Sida du $1^{\circ}$ France: tendances actuelles-Journée

3 Rotily M, Galinier-Pujol A, Obadia Y, Moatti JP, Toubiana P, 3 Rotily M, Galinier-Pujol A, Obadia Y, Moatti JP, Toubiana P, Vernay-Vaisse C, et al. HIV infection and associated risk
factors among inmates in south eastern French prisons. AIDS 1994;8:1341-

4 Vernay-Vaisse C, Rotily M, Galinier-Pujol A, Rousseau S, Bourlière $\mathrm{M}$, Obadia Y. Epidémiologie des hépatites virales $\mathrm{B}$ et $\mathrm{C}$ : évaluation d'un programme de dépistage et de vaccination au centre pénitentiaire de Marseille. Rev Epidemio Sante Pub 1997;45(suppl 1):42-3.

5 Holsen DS, Harthug S, Myrmel H. Prevalence of antibodies to hepatitis $\mathrm{C}$ virus and association with intravenous drug abuse and tattooing in a national prison in Norwav. Eur J Clin Microbiol Infect Dis 1993;12:673-6.

\section{Children with enuresis}

\section{Nowadays, a strong suspicion of sexual} abuse would prompt full investigation

EDITOR-Gosnell has written a moving piece about his experience of childhood enuresis, unsuccessful behavioural and pharmacological treatments, and the fact that in retrospect he attributes the enuresis and hence the failure of treatment to his experience of being regularly sexually abused by an older relative. ${ }^{1}$ He highlights the silent but miserable stance in which sexually abused victims are frequently placed and how difficult it can be for them to break the silence. He recognises that often these children feel insecure and need time to build up trust in the people offering help, and he suggests that long term psychotherapy should be offered as a first line treatment.

Unlike in the 1960s, it is now more widely recognised that children who have been sexually abused may present with a range of symptoms, including enuresis. The enuresis, however, is much more commonly part of a wider picture of emotional or behavioural disturbance, or both. A strong suspicion of sexual abuse would prompt investigation, plans to ensure the safety of the child, and a fuller assessment regarding what form of psychotherapy was indicated.

While acknowledging the link between enuresis and sexual abuse, it is important to recognise that there are children who present with "simple" enuresis, with no other associated features of psychological disturbance, who are unlikely to have been abused and who benefit from behavioural interventions such as enuresis alarms and "star charts." It would be inappropriate and hugely expensive to suggest that these children undergo long term psychotherapy; in fact, the child and family would probably vote with their feet.

Gosnell's article highlights the need for recognition of the existence of child sexual abuse; the fact that it occurs far more commonly within the circle of known family and friends than with strangers; the diversity of possible clinical presentations; and the need for mental health services and other agencies dealing with abused children to have the resources to assess these children and provide them (and their families where appropriate) with appropriate therapeutic care.

Fiona C M Forbes Consultant child and adolescent psychiatrist

Child and Family Mental Health Service, Edinburgh Sick Children's NHS Trust, Edinburgh EH9 1LI

1 Gosnell J. Enuresis-the cause that dares not speak its name. BMJ 1997;315:435. (16 August.)

\section{Most cases of primary nocturnal enuresis are caused by isolated developmental immaturity}

Editor-I read with admiration Gosnell's Personal View about his experience of living with enuresis. ${ }^{1}$ As a paediatrician working with many families and children where there has been sexual abuse, I am aware of the immense trauma that this causes and the fact that many victims do not disclose their abuse until adulthood, if ever. However, sexual abuse as a cause of nocturnal enuresis needs to be put into context.

The vast majority of cases of primary nocturnal enuresis are caused by isolated developmental immaturity, and a tenth of 5 year olds may never have had a dry bed. I should hope that, in assessing the possible causes of enuresis, all doctors would consider psychological as well as physical 
and developmental origins. Sexual abuse is certainly well recognised now as a possible cause of (particularly secondary) nocturnal enuresis, and strenuous efforts should be made to elucidate the causes of psychological trauma in this smaller group of children with secondary nocturnal enuresis.

I would hope that treatments are more individually tailored to a child's needs than was the case in the 1960s and early '70s, with clear details being collected about each child's sleeping arrangements. One should never forget the possibility of abuse of any kind, but overzealous probing should be avoided for most children with primary enuresis. Such probing will only add to the distress of many parents.

L Light Consultant community paediatrician Premier Health, Greenhill Health Centre, Lichfield WS13 6JI

Gosnell J. Enuresis-the cause that dares not speak its name. BMJ 1997;315:435. (16 August)

\section{Maybe general surgery no longer exists as a specialty}

EDITOR-Corvera amd Kirkwood outline advances in several aspects of general surgery for which evidence suggests that specialisation produces better patient outcomes. ${ }^{1}$ Indeed, if one excludes these topics from the review, nothing remains. This begs one question: is there such an entity as "general surgery" today?

Allan D Spigelman Professor of surgical science University of Newcastle, Division of Surgery, John Hunter Hospital, Newcastle, New South Wales 2310, Australia

Corvera CU, Kirkwood KS. Recent advances in general surgery. BMJ 1997;315:586-9. (6 September.)

\section{Is histological examination of tissue removed by GPs always necessary?}

\section{Even specialists get the clinical diagnosis wrong}

EDITOR-Because of increasing workloads and perceived lack of important diagnoses Lowy et al advocate that general practitioners should not routinely send skin tissue specimens for histological diagnoses unless they "have even a slight suspicion that the lesion may be serious." As a histopathologist I agree that the vast majority of skin biopsy specimens from general practice are of no clinical consequence. However, this can be said only when the specimens have been sent for histological examination.

Most general practitioners who excise skin biopsy specimens are not trained dermatologists, and even the most "obvious" clinical lesion may not turn out to be what it was thought to be. This happens even to experienced specialist surgeons. A policy of selective histological referral when the doctor is not necessarily an expert dermatologist will certainly miss important diag- noses, but it also misses the basic point that these specimens are diagnostic and, once lost, can never be retrieved. It is also, I would argue, on dubious grounds legally if complications should develop. I am unaware of any histology department that has succumbed to "laboratory chaos," patient are grateful for the dialogue and reassurance that examination of these specimens gives them. I will certainly not be changing my advice to general practitioner colleagues on the basis of this article alone.

P Cross Consultant histopathologist Department of Cyto-Histopathology, Queen Elizabeth Hospital, Gateshead NE9 6SX

1 Lowy A, Willis D, Abrams K. Is histological examination of tissue removed by general practitioners always necessary? Before and after comparison of detection rates of serious Before and after comparison of detection rates of
skin lesions. BMJ 1997;315:406-8. (16 August.)

skin lesions. $B M J$ 1997;315:406-8. (16 August.)
2 Slater D. Screening in the 1990 contract. BMJ 1990;300:

\section{Clinically important skin lesions would have been missed with a selective histological approach}

EDITOR-Lowy et al compare a selective and non-selective approach by general practitioners to submission of skin lesions for histological assessment. ${ }^{1}$ They suggest that histological evaluation of all tissue specimens is work intensive, is not a cost effective means of detecting serious skin pathology, and does not pick up clinically important lesions that could have been missed by a more selective approach.

We performed a 25 year retrospective analysis of all histologically confirmed malignant melanomas diagnosed in our university hospital dermatology department, comparing prior clinical diagnosis with histological outcome. ${ }^{2}$ The incidence of melanoma was low and varied substantially from year to year (range 6-22 cases a year). A firm clinical diagnosis of malignant melanoma was made before histological examination in only 98 of the 238 specimens, although a malignant or premalignant condition was suspected in 204 cases. Of the 34 in which a malignancy was unsuspected, most (21) were benign melanocytic naevi. This indicates both the difficulty of diagnosing malignant melanoma and the potential dangers of a selective approach to histological assessment.

Excised benign skin lesions yield predominantly four diagnoses: melanocytic naevi, seborrhoeic keratoses, viral warts, and skin tags. We undertook a clinical and histological review of 1000 benign lesions removed in our department during 1990-2 for which a firm clinical diagnosis of one of these lesions had been made. Histological assessment showed that clinical misdiagnosis occurred in 150 lesions. The histological diagnosis was usually another benign skin lesion, but seven malignant tumours (six basal cell carcinomas and one squamous cell carcinoma) and eight premalignant lesions (two Bowen's disease and six actinic keratoses) had been missed clinically.

These results underline the importance of sending tissue samples for histological examination. Moreover, the general practices that Lowy et al studied were self selected and performing frequent biopsies; the case for rationing histological assessment might be weaker if all practices performing biopsies had been included.

Richard Parslew Senior registrar

Lesley Rhodes Consultant

Department of Dermatology, Royal Liverpool and Broadgreen Hospitals Trust, Liverpool L69 3BX

1 Lowy A, Willis D, Abrams K. Is histological examination of tissue removed by general practitioners always necessary? Before and after comparison of detection rates of serious skin lesions. BMJ 1997;315:406-8. (16 August.)

2 Parslew RAG, Rhodes LE. Accuracy of diagnosis of benign skin lesions in hospital practice: a comparison of clinical and histological findings. Journal of the European Academy' of Dermatology and Venereology (in press).

Over 10 days two important lesions were sent to histopathologists in Sheffield

EDITOR-Lowy et al's paper ${ }^{1}$ prompted our laboratory to consider our experience with biopsies done by general practitioners and the value of examining the samples obtained. We presume that we do not see all tissues biopsied from the practices we serve and thus cannot predict what impact a policy of submitting all such tissue to our laboratory would have. However, we consider the question posed by this study to be whether it is worth $£ 18$ to request histological assessment if one is confident with the diagnosis clinically.

We believe that we have able and dutiful general practitioners locally (comparable to those in the authors' study), from whom we receive 1500 samples annually. Last year these general practices sent us 14 adnexal neoplasms, 18 soft tissue benign tumours, 11 squamous carcinomas, 24 basal cell carcinomas, two malignant melanomas, and one dysplastic naevus, although the bulk of their work comprises benign and common lesions. Since we cannot retrospectively assess whether these more important neoplastic lesions would have been referred if fewer samples were sent, we cannot address the above economic question directly.

In the 10 working days after Lowy et al's article was published we received one malignant melanoma of $3 \mathrm{~mm}$ thickness and one incompletely excised trichoepithelioma, which had been clinically assessed as a benign melanocytic naevus and a seborrhoeic keratosis respectively. This is not a criticism of the practitioners in question but indicates the weakness of not submitting cases for diagnosis. Both cases require further surgery, with one clearly being of major prognostic importance.

To reduce the submission of cases, we believe, would ultimately be self defeating. Firstly, the audit cycle, reflecting clinical diagnosis and assessment of the surgical margin, would suffer in the absence of a pathology report. Secondly, a proportion of patients would be denied prompt and relevant subsequent treatment, ultimately requiring more aggressive treatment. Thirdly, it is inevitable that some would be beyond treatment by the time the error had been realised. Finally, one cannot defend in cases of litigation if the prior surgical evidence has been discarded. 
We believe that, although well intentioned, this paper has potentially damaging consequences for the general population. The question of pathology assessment is reduced to one of economics, revolving around the sum of $£ 18$. This figure is less than half the cost of a maintenance pack of $20 \mathrm{mg}$ omeprazole being taken daily for reflux disease. ${ }^{2}$ It is good value if you have a sinister lesion masquerading as a benign entity.

S K Suvarna Consultant pathologist

J R Shortland Consultant pathologist

J H F Smith Consultant pathologist

Department of Histopathology, Northern General

Hospital NHS Trust, Sheffield S5 7AU

1 Lowy A, Willis D, Abrams K. Is histological examination of tissue removed by general practitioners always necessary? Before and after comparison of detection rates of serious Before and after comparison of
skin lesions. BMJ 1997;315:406-8.

2 British Medical Association and Roval Pharmaceutical

Society of Great Britain. British national formulary. Society of Great Britain. British nationd
London: BMA, RPS, 1997:39-40. (No 33.)

\section{Authors' reply}

EDITOR-Surprisingly, all the correspondents write as if we had recommended reductions in general practitioners' referral of biopsy specimens for histological examination, or rationing of pathology services. Our paper unambiguously described an intervention that sought to increase use of histological examination from its current level to $100 \%$. No inference is possible on the effect of reducing referrals; we certainly did not imply that this would be safe. On the contrary, we took pains to point out that specimens should continue to be referred on the slightest suspicion.

Our result does not support Kirby et al's expectation of "a much higher detection of basal ... and squamous cell carcinomas" if the intervention were applied nationally. Similarly, Cross states that a selective policy would "certainly miss important diagnoses" but does not explain why his certainty is unaffected by our research evidence.

Parslew and Rhodes are concerned that our sample of general practitioners may have missed incompetent doctors. We have no evidence of this, and our high response rate suggests that the sample was broadly representative, but we cannot exclude this possibility. On the other hand, precisely because the doctors in the study were volunteers we may have overestimated the increase in referrals achievable nationally. We believe that our study gives the best insight available into what might realistically be achieved in practice.

Cross refers to the value of reassurance and Suvarna et al to the benefits of feedback. We agree, but did not attempt the difficult task of quantifying these because the main argument for referring everything has always been that important diagnoses would otherwise be missed. If this is untrue the policy decision rests on less tangible benefits.

We do not understand why some of the respondents believe that examining everything is a medicolegal imperative. It should not be necessary to order investigations for defensive reasons when clinical judgment suggests they are not needed; noninvestigation is accepted as reasonable behaviour in many situations throughout medicine.

We share Kirby et al's feelings about the death toll from melanoma, but our study found no evidence that extending histological coverage would help.

Parslew and Rhodes and Suvarna et al confirm doctors' diagnostic fallibility, but, as with all previous research, their data say nothing about what gets discarded. Our study is unusual in providing an insight into these "missing" lesions. The fact that we found no evidence that they include malignancies is obviously relevant to the debate about whether general practitioners are competent to continue making selective use of histology, as they do of all other investigations.

Adam Lowy Lecturer in epidemiology Keith Abrams Senior lecturer in medical statistics Department of Epidemiology and Public Health, University of Leicester, Leicester LE1 6TP

Diane Willis Research associate

Greenwood Institute of Child Health, Leicester LE3 0QU

\section{More skin carcinomas might be detected} with routine histological examination

EDITOR-Lowy et al ask whether histological examination of tissue removed by general practitioners is always necessary. ${ }^{1}$ We would answer an unequivocal yes, agreeing with the recommendations of the Royal College of General Practitioners that pathological examination should be mandatory. ${ }^{2}$ Lowy et al reported previously that general practitioners made an inaccurate diagnosis in $58.8 \%$ of cases in 1990 and $50.0 \%$ in 1991 . De Berker commented at that time that, with such a low diagnostic rate, not sending tissue for histological examination was probably foolhardy. ${ }^{4}$ This inaccuracy in diagnosis is highlighted in the current study, in which 31 malignant melanomas were removed; presumably they had not been diagnosed before excision. We have reported that these misdiagnoses can have serious repercussions for the patient's management. ${ }^{5}$

The authors concede that because numbers were small they could not rule out that a small increase in the detection rate of malignant melanoma would occur if their intervention-referral of tissue for histological examination-were to be carried out nationally. If this is the case, a much higher detection rate of basal cell carcinomas and squamous cell carcinomas (which are more common than melanoma) might be expected if this intervention were to be extended.

Previous reports have commented on the high rate of inadequate excision of skin malignancies by general practitioners. Not knowing the pathology of the tissue can only lead to recurrences, which may require comparatively expensive interventions such as Mohs' surgery rather than the simpler procedures that can be used if the inadequacy of excision is discovered immediately. We believe that the proportion of tissue samples currently being sent for histo- logical examination (around 40\%) is inadequate. It would be a tragedy for both patient and doctor were a seemingly harmless lesion discarded and a young life lost because of a missed melanoma. It would also be medicolegally disastrous.

Brian Kirby Specialist registrar in dermatology Philip V Harrison Consultant dermatologist Queen Victoria Hospital, Morecambe, Lancashire LA4 5NN

Robert Blewitt Consultant pathologist Royal Lancaster Infirmary, Lancaster LA1 4RP

1 Lowy A, Willis D, Abrams K. Is histological examination of tissue removed by general practitioners always necessary? Before and after comparison of detection rates of seious skin lesions. $B M J$ 1997;315:406-8. (16 August)

2 General Medical Services Committee, Royal College of General Practitioners in collaboration with Royal College of Surgeons of England, Royal College of Surgeons of Edinburgh, British Society for Dermatological Surgery, Joint Committee on Postgraduate Training for General Practice. Minor surgery in general practice: guidelines. London: RCGP, 1996.

3 Lowy A, Brazier J, Milner A, Fall M. Quality of minor surgery by general practitioners in 1990 and 1991. Br J Gen Pract 1994;44:364-5.

4 De Berker D. Quality of minor surgery in general practice. BrJ Gen Pract 1994;45:53.

5 Harrison P, Blewitt R. Referrals from general practice to hospital out-patient departments. BMJ 1989;299:1101.

\section{Responsibility for decision to give transfusion remains with doctor, not patient}

EDITOR-In an editorial on consent for transfusion Williams identified two key issues: whether consent for transfusion is appropriate and whether it is valid. ${ }^{1}$ The author stated that the controversy does not hinge on the need to inform patients adequately. We dispute this and propose that, if done adequately, this is exactly the factor that ensures that consent is both appropriate and valid, regardless of whether a formal consent form is signed by a patient in the presence of a healthcare professional.

The fact that transfusion of blood products carries a considerable material risk is unlikely to be challenged, and a doctor with adequate training will be able to balance this risk against the risk of not giving a transfusion. The doctor must then make his or her recommendation to the patient, which after discussion will almost always be accepted. The duty of the medical profession is to regulate to ensure that its practitioners are adequately trained to make such decisions correctly on behalf of their patients. The signature of a patient on a consent form does not mean that he or she assumes responsibility for the decision to give a transfusion; this remains with the doctor.

Williams raises several issues regarding the validity of consent. The task of gaining consent almost always falls to the most junior member of the clinical team. Studies have shown this to be inappropriate in the case of surgery ${ }^{2}$ and coronary angiography, ${ }^{3}$ and there is no reason to believe that junior doctors do a better job with transfusion. The decision to treat patients with blood products must come from a more senior source, at which point the process of informed consent will begin. If specialist 
nurse transfusionists have more time than the medical staff to discuss the issues behind the decision and the balance of risks then they will have an important role.

The answers to the problem lie in some of Williams's recommendations-namely, better audit of transfusion practice, better education of medical and nursing staff, the use of specially trained nurse transfusionists, and better communication between the medical and legal professions. The role of the medical team in gaining informed consent, whether written or not, is to ensure that the patient understands clearly that transfusion is the most appropriate treatment. This takes time and discussion. The signature of a patient on a consent form will not absolve the doctor of the responsibility to make appropriate clinical decisions and discuss them with the patient.

Nigel G B Richardson Specialist registrar in surgery Patricia M Jones Specialist registrar in anaesthesia St George's Hospital, London SW17 0RE

1 Williams FG. Consent for transfusion. BMJ 1997;315: 380-1.(16 August)

2 Richardson N, Jones P, Thomas M. Should house officers obtain consent for operation and anaesthesia? Healt rends 1996;28:56-9.

3 Langford E, de Belder A. Consent procedure for coronary angioplasty is haphazard. $B M J$ 1997;314:1762. (14 June.)

\section{Incidence of epilepsy is now higher in elderly people than children}

EDITOR-We were surprised by Neville's statement, in his review on epilepsy in childhood, that "epilepsy starts in childhood in $60 \%$ of cases." Although this was possibly the case more than 20 years ago, recent evidence suggests otherwise.

The United Kingdom national general practice study of epilepsy, a prospective population based study, found that in 564 definite incident cases recruited between 1984 and 1987 , only $25 \%$ of patients were aged under $15 .^{2}$ Furthermore, while children undoubtedly have the highest incidence of epilepsy among people aged under 65 , strong evidence has emerged that seems to confirm a recent secular trend in the age specific incidence of epilepsy, with a decline in incidence in children and a shift towards elderly people. ${ }^{3-5}$ The incidence of epilepsy in the elderly population, at least in community based studies from developed countries, is now frequently reported as being between 100 and 140 per $100000^{35}$ (and possibly much higher in subjects over 80 years old), which is far greater than the overall incidence of epilepsy. ${ }^{35}$

No clear explanation for these changes has emerged, though several factors are probably involved. It has been suggested that improvements in medical antenatal and perinatal care, coupled with increased awareness of the necessity for expectant mothers to adopt healthier lifestyles, may have played a part in the decline in the incidence of childhood epilepsy by way of decreases in the incidence of malformations of cortical development and birth hypoxia, but this remains speculative. ${ }^{3}$ Among elderly people, increased life expectancy has inevitably led to a larger population at risk; elderly people are anyway susceptible to cerebrovascular disease, which is by far the commonest cause of seizures in this age group. ${ }^{35}$ Although the incidence of overt cerebrovascular disease has paradoxically decreased in the community over the past two decades ${ }^{5}$ it is possible that small vessel cerebrovascular disease in subjects with newly diagnosed seizures who are otherwise asymptomatic may be responsible for this discrepancy. Population based studies of epilepsy that apply high resolution magnetic resonance imaging to incident cases in all age groups will help resolve some of these issues.

Alex D Everitt Research registrar in neurology Josemir W Sander Senior lecturer in neurology Epilepsy Research Group, Institute of Neurology, London WC1N 3BG

1 Neville BGR. Epilepsy in childhood. BMJ 1997;315:924 30. (11 October.)

2 Sander JWAS, Hart YM, Johnson AL, Shorvon SD. The national general practice study of epilepsy: newly diagnosed seizures in a general population. Lancet 1990; 336:1267-71.

3 Sander JWAS, Shorvon SD. Epidemiology of the epilepsies. J Neurol Neurosurg Psychiatry 1996;61:433-43.

Cockerell OC, Eckle I, Goodridge DMG, Sander JWAS, Shorvon SD. Epilepsy in a population of 6000 (n) Prever 1995;58:570-6.

5 Hauser AW, Annegers JF, Kurland LT. Incidence of epilepsy and unprovoked seizures in Rochester, Minnesota, 1935-1984. Epilepsia 1993;34:453-68.

\section{Community institutional care for frail elderly people}

"Unitary care" homes might be the answer

EdiToR-Black and Bowman rightly emphasise the importance of preadmission assessment and ongoing medical supervision in caring for frail elderly people. ${ }^{1}$ Current practice in many areas does not provide for formal specialist input at the time of admission and undoubtedly some older people are moving into homes prematurely. The pressure to clear beds leads to inadequate opportunities for rehabilitation and the possibility of missing remediable disease. Furthermore, the balance of local provision between residential and nursing homes may encourage misplacement in both directions. A recent survey of new admissions to nursing homes noted that $23 \%$ of residents funded by the local authority, when independently assessed, were not dependent on nursing. ${ }^{2}$ These people seemed more suited to a residential environment, and some could possibly have stayed in their own homes given sufficient time, rehabilitation, and community support.

A more radical suggestion about the overlapping nature of residential and nursing institutional provision would be to move towards a "unitary care" home, with a dependency matched scale of charges. Closer integration of health and social work provision has long been advocated and would allow many anomalies to be resolved. Joint ownership of the issues would lead to responsible and responsive organisation of services rather than the present buckpassing and lack of coordination, which often reflects funding shortfalls and the absence of realistic resource transfers.

With regard to the provision of continuing care for most frail elderly people, the lack of mention of ongoing NHS responsibility for those requiring specialist care was surprising. Some health authorities have not clearly recognised their obligation to provide continuing NHS care for those too complex for the primary care and nursing home sector. Recent guidance is definitive, though the scale of such provision is not specified. However, the need for increased support for both nursing homes and primary care is long overdue. Black and Bowman's third and fourth options may be similar in practical terms, and both should be explored further as a matter of urgency. To provide good care for this complex population requires investment by both primary and secondary care and the development of closer working relationships. More doctors should be encouraged to take the diploma of geriatric medicine, and the training programmes for specialist registrars must cover the competencies relating to continuing care of elderly people. The speciality risks having to rediscover itself if these issues are not addressed soon.

William R Primrose Consultant physician Department of Medicine for the Elderly, Woodend Hospital, Aberdeen AB15 6LS

I Black D, Bowman C. Community institutional care for frail elderly people. BMJ 1997;315:441-2. (23 August.)

2 Newnham DM, Berrington A, Primrose WR, Seymour DG. Self-funding and community care admissions to nursing homes in Aberdeen. Health Bull 1996:54:301-6.

\section{A multidisciplinary, multiagency approach should be the rule}

EDitor-While welcoming Frank Dobson's call for social services to fund placements for elderly hospital patients, ${ }^{12}$ we are concerned about the potential for indiscriminate and inappropriate transfer of frail elderly people out of hospital.

Like many trusts we face the problem that social services are unable to fund appropriate nursing home placement while accepting liability. The inevitable consequences are prolonged, inappropriate hospital stay; bed blocking; and cancellation of elective surgery. As a trust we have experience of using nursing home beds in an emergency and as a planned procedure. In an emergency, when selection is by departments unaccustomed to assessment of complex medical and social risks, inappropriate placement can ensue, with surgically fit but medically ill patients requiring readmission at a later date.

We recently piloted a scheme in which geriatricians screened and selected inpatients. These patients were placed in nursing homes but remained the responsibility of the trust both clinically and financially. The scheme ensured that only patients who were medically stable and who had had appropriate hospital based rehabilitation were moved. Continuation of multidisciplinary input was ensured by a team of therapists 
and specialist nurses. Of more than 420 patients transferred to nursing homes, 102 (24\%) required social services funding for continuing care. The remainder went home with care packages. The main obstacle to discharge from trust care was the excessive time patients spent waiting for previously agreed funding from social services.

What is needed is a joint strategy of care so that elderly people can get the medical care and rehabilitation they need in accessible locations. A multidisciplinary, multiagency approach should be the rule, and the lead responsibility for care management should be mutually agreed between the agencies concerned for each person. Black and Bowman's article is a welcome addition to the debate on whether commissioning is to be within a national framework or to develop according to local pressures. ${ }^{3}$ In our experience, indiscriminate transfer has been ineffective and has caused dissatisfaction. Dobson's support for the process of discharge and assumption of responsibility by social services is welcome, but hospitals must ensure that the right people are sent and that they are able to share in ongoing care when necessary. The role of the geriatrician as advocate and ongoing support to frail elderly people is paramount. Elderly people have complex problems, and forcing simplistic solutions risks failure to deliver appropriate care.

D Mukherjee Consultant geriatrician Helen Newton Consultant geriatrician David Howard Consultant geriatrician St Margaret's Hospital, Swindon SN3 4QP

1 Silvester R. Elderly to be moved in NHS bed crisis. Daily Telegraph 1997 Aug 19.

Coulson J. New Labour, new money-but no blank cheque BMA News Rev 1997 Aug:14-6.

3 Black D, Bowman C. Community institutional care for frail elderly people. $B M J$ 1997;315:441-2. (23 August.)

\section{Rapid tranquillisation protocol had been published}

EDITOR-Kerr and Taylor claim that the rapid tranquillisation protocol we recommend $^{1}$ is a "a simplified version" of a scheme they developed. ${ }^{2}$ In fact, our recommendations were based on a regimen that has been in widespread use for several years,,${ }^{34}$ modified by our personal experience and that of colleagues in trusts throughout the country. We used the Maudsley algorithm for illustration because it is one of the few to be published and thus easily available to others. ${ }^{5}$ The points they make relating to prevention, context, and non-pharmacological measures were all covered, albeit briefly, in the original article.

Teifion Davies Senior lecturer in community psychiatry

United Medical and Dental Schools of Guy's and St Thomas's Hospitals, St Thomas's Hospital, London SE1 7EH

Zerrin Atakan Consultant psychiatrist Psychiatric Intensive Treatment Unit, Lambeth Healthcare NHS Trust, London SW9 9NT

1 Atakan Z, Davies T. ABC of mental health: mental health emergencies. BMJ 1997;314:1740-2. (14 June.)
2 Kerr IB, Taylor D. Mental health emergencies. BMJ 1997;315:885. (4 October.)

3 Cookson J, Crammer J, Heine B. The use of drugs in psychiatry. 4th ed. London: Gaskell, 1993:112-7.

Bazire S. Psychotropic drug directory. Dinton, Wiltshire: Quay Books, 1995.

Maudsley prescribing guidelines. London: Bethlem Royal and Maudsley Hospitals, 1995

\section{Article about Mental Health Act was misleading}

EDITOR-Barker's article about mental health and the law is muddled and, in some instances, wrong in its discussion of the Mental Health Act (1983). ${ }^{1}$ For example, the only requirement under the act with regard to medical recommendations for admission under section 2 or 3 is that one of the doctors must be approved under section 12(2). The article perpetuates the myth that one of the doctors must have prior knowledge of the patient, whereas the act is clear in stating that one recommendation "shall, if practicable" be given by a doctor with "previous acquaintance"-patients can be, and are, legally detained even though neither doctor has ever met the patient before, although this is uncommon.

It is a travesty of the act to say that it is only in certain circumstances that the nearest relative may make an application for admission; in fact, such relatives are just as entitled to make an application as an approved social worker, although in practice the social worker is much more likely to do so. Incidentally, in the wording of the act the nearest relative is mentioned before an approved social worker

Lastly, it is misleading to say that both psychopathic disorder and mental impairment must be considered treatable before admission to hospital is warranted. This is true only for admission under section 3 (reasonably enough, since this is a treatment order); it is false in terms of section 2, which covers the four legal categories of mental disorder "and any other disorder or disability of mind." The definition of treatable is worth stating, since the act mentions that treatment must be "likely to alleviate or prevent a deterioration of [the patient's] condition," and the second part of the phrase is sometimes forgotten.

Barker missed the opportunity to provide an authoritative and clear account of the law in England and Wales relating to mental health. She also missed the opportunity to emphasise some of the idiosyncrasies involved, such as the specific statement that the act does not apply to people who seem to be suffering from mental disorder "by reason only of promiscuity or other immoral conduct, sexual deviancy or dependence on alcohol or drugs."

The views expressed are the author's and not those of the Medical Defence Union.

T H Leigh Senior medical claims handler, Medical Defence Union

58 Walkerscroft Mead, London SE21 8LJ

1 Barker A. ABC of mental health: mental health and the law. BMJ 1997;315:590-2. (6 September.)

\section{Self help groups and professionally conducted group interventions are different}

EDITOR-Watts's letter about cancer self help groups is misleading. ${ }^{1}$ For example, the author refers to Fallowfield as having undertaken a review on self help or support groups, ${ }^{2}$ yet this article was a simple comment on a review by Meyer and Mark. In addition, Watts refers to Spiegel et al's study, which reported details of survival gains ${ }^{4}$; but this study had numerous methodological flaws, which have been pointed out by several authors. ${ }^{5}$ Watts, however, fails to alert readers to these major problems.

Watts confuses self help groups with professionally conducted group interventions. For example, in Spiegel et al's study, groups were run by a psychiatrist or a social worker with a therapist and included weekly sessions with hypnosis. This approach is vastly different from that typically seen in self help groups. Evidence for the value of self help groups is extremely limited. Studies investigating group interventions with patients with cancer are difficult, and studies involving self help groups are invariably less robust in design than those conducted by professionals and examining the potential of interventions to improve patients' wellbeing. Self help groups should not be confused with groups conducted by professionals.

Watts is correct in pointing out that some professional groups are effective at reducing emotional suffering. However, only a few studies using group approaches have been reported in Britain, and many studies included in reviews such as that by Meyer and Mark $^{3}$ are based on North American populations. We have no way of knowing the transferability of these types of group to a British population.

Watts states that oncologists do not routinely recommend patients to self help groups. This may be correct, but is such behaviour inappropriate? Why should patients be routinely recommended to self help groups? On the basis of the evidence we have, there is little understanding of the clinical value of self help groups. Much more research on the various types of interventions is needed before we advocate self help groups to all patients with cancer.

Andrew Bottomley Consultant, psychosocial research and development

Cancer Support Centre, Bradford BD9 6RN

Ronald Thomas Retired psychologist Edtext International, Palmerston North, New Zealand

1 Watts EJ. Cancer self help groups are underused. BMJ 1997:315:812. (27 September)

2 Fallowfield L. Psychosocial interventions in cancer. BMJ 1995;311:1316-7.

3 Meyer TJ, Mark MM. Effects of psychosocial interventions with adult cancer patients: a meta-analysis of randomised experiments. Health Psychol 1995;14:101-8.

4 Spiegel D, Bloom JR, Kraemer HC, Gottheil E. Effect of psychosocial treatment on survival of patients with metastatic breast cancer. Lancet 1989; ii:888-91.

5 Fox B. Some problems and some solutions in research on psychotherapeutic intervention in cancer. Supportive Care Cancer 1995;3:257-63. 